\title{
Quantitative comparison of radar QPE to rain gauges for the 26 September 2007 Venice Mestre flood
}

\author{
A. M. Rossa, G. Cenzon, and M. Monai \\ Centro Meteorologico di Teolo - DRST, ARPA Veneto, Via Marconi 55, 35037 Teolo (PD), Italy \\ Received: 16 April 2009 - Revised: 9 December 2009 - Accepted: 11 December 2009 - Published: 23 February 2010
}

\begin{abstract}
In this study consideration is given to the potential use of radar-derived quantitative precipitation estimates (QPE) as flash flood guidance in the context of the Italian Civil Protection flood risk management system. The interest in high precipitation intensities and accumulation motivated the case study of the 26 September 2007 event, in which a quasi-stationary mesoscale convective system brought within 3-6h $40 \%$ of the mean annual precipitation to the wider Venice-Mestre area, i.e. $260 \mathrm{~mm}$ in Venice-Mestre and $325 \mathrm{~mm}$ in closeby Valle Averto.

Comparison of the radar-derived QPE in the area with the rain gauge network revealed a good correspondence for warm season rainfall, both for daily accumulations in the longterm (about 2 years) and hourly accumulations for the case under consideration. The long term average radar to gauge ratio is very close to $0 \mathrm{~dB}$ with an uncertainty of approximately $\pm 3 \mathrm{~dB}$, i.e. roughly a factor of two, slightly better for higher precipitation intensities. For the hourly accumulations during this very intense event the spread is similar, while the average is slightly positive.

The locations of the rainfall accumulation maximum as detected, respectively, by the radar and by the rain gauge network do not coincide. Given the relatively good quality of the precipitation estimation, it is argued that these areas effectively have received even larger rainfall amounts, and that it is worthwhile to further investigate the potential of radar to be used as flash flood guidance.
\end{abstract}

\section{Introduction}

In 1992 the Italian National Department of Civil Protection (DPCN) was conferred the responsibility to promote public safety and to protect the lives and property of the Italian

Correspondence to: A. M. Rossa

(arossa@arpa.veneto.it) citizens by setting up an organization able to perform an effective emergency management (Italian-Government, 1992, 2000). Within the palette of natural hazards the hydrometeorological hazard is a relatively frequent one and can constitute a major threat to life and property. In a relatively recent Directive of the President of the Council (ItalianGovernment, 2004) operational guidelines were laid out for the national and regional alert management related to the hydrogeological and hydraulic risk. The alert system is built on concerted operations of national and regional units of Civil Protection on one side and hydrometeorological monitoring and forecasting services on the other.

A first implementation of this hydrometeorological alert system relies on empirically determined flash flood guidances, i.e. rain gauge-derived threshold values for the alert areas into which the Italian territory has been subdivided. These values are specific for a given watershed and depend on the time period in which a certain amount of precipitation is expected, as well as on the antecedent moisture conditions of the soil. The flash flood guidances are evaluated on the basis of local and regional rain gauge networks and corresponding stream flow observations, and rely on point observations which are assumed to be representative for a given area with a typical size of the order of $100 \mathrm{~km}^{2}$ for a dense network. In the case of severe and localized convection the rain gauge network does not necessarily sample the maxima of the precipitation so that the flood warning could be underestimating or late for the given area. This implementation is subject to improvement, for instance by making use of the relatively dense radar coverage in Italy to achieve better spatial coverage, or numerical weather prediction guidance at short and medium range to extend the warning lead time (Rotach et al., 2009). Germann et al. (2006) report that the Swiss National Meteorological Service operates an automated alert system based on their radar network and highlight the high demands put on the accuracy of radar estimates.

Published by Copernicus Publications on behalf of the European Geosciences Union. 
Meteorological radars, by virtue of their high spatial and temporal resolution, are a natural means for monitoring precipitation events and, therefore, are an optimal candidate for an improved flood warning tool. Radars typically deliver quantitative precipitation estimates (QPE) on a onekilometer grid every $10 \mathrm{~min}$, or less. This is especially relevant in view of the deployment of hydrological models, which have become spatially distributed and provide a basis for an effective use of such data (Zappa et al., 2008; Germann et al., 2009).

Unfortunately, the error characteristics of radar derived QPE can be very variable both in time and space. The error sources are well known and documented (Michelson et al., 2004), but systematic description or quantification of the uncertainty is still subject of current applied research. As a matter of fact, in the framework of the ongoing COST 731 Action "Propagation of Uncertainty in Advanced MeteoHydrological Forecast Systems" (Rossa et al., 2010) several approaches to translating radar QPE quality information into quantified uncertainty are explored (Germann et al., 2009; Sempere-Torres et al., 2008). They use the statistical properties of the error to construct equiprobable QPE ensemble members which span a sort of envelope of possible outcomes effectively yielding an uncertainty band. These ensemble members can then be fed as input to a hydrological model to produce an ensemble of streamflow simulations which allow the evaluation of the probability of exceedance of some critical flow level (Germann et al., 2009).

Attenuation can be a major source of underestimation when the radar beam propagates across regions of intense precipitation, especially at wavelengths of C-band and smaller (e.g., Hitschfeld and Bordan, 1954). Dual polarization radars help, to some extent, correct for attenuation effects by taking into account phase measurements. Without dual polarization capabilities the impact of attenuation on QPE is strongly dependent on where relative to the radar the intense precipitation is occurring, while correction is very difficult (e.g., Illingworth, 2004). The recent renewed interest in X-band radar technology has significantly pushed the research for methods to correct for attenuation, most of which are based on dual polarization and/or redundancy (Testud, 2004; Gorgucci and Chandrasekar, 2005).

In the present study the question is investigated whether QPE derived from the Veneto radar network has the potential for being used quantitatively for flash flood guidance. It is addressed for the case of an extreme rainfall event which took place 26 September 2007 in the area of Venice Mestre, while an analysis for two warm seasons provide the statistical background. Rain gauge observations are compared with the radar derived QPE of the network of ARPA Veneto, the Regional Agency for Environmental Protection and Prevention of Veneto. Section 2 briefly outlines the ARPA Veneto monitoring network, Sect. 3 describes the dynamics and the precipitation of the event, while Sect. 4 reports the radar QPE analysis. Conclusions are given in the final Sect. 5.

\section{Observational data}

Observations used for this analysis were acquired from the automatic weather station (AWS) network of the Regional Agency for Environmental Protection and Prevention of Veneto (ARPAV), which totals roughly 200 stations, and the two C-band Doppler radars located on Mt. Grande (472 m a.s.1.) on the central part and at Concordia Sagittaria (10 m a.s.l.) on the eastern part of the Veneto plain (Fig. 1). The real time rain gauge network consists of 161 tipping bucket gauges. The products used in this study are:

- rain gauge quantitative precipitation estimates (QPE) in hourly and daily accumulation;

- radar-derived quantitative precipitation estimates (QPE) in hourly and daily accumulation.

The two radars are EEC single polarization Doppler radars working at C-band. Their data are post processed by the Hydrometeorological Decision Support System HDSS (Conway et al., 2007). Here a number of quality control algorithms are applied and surface QPE is derived in the QPE-SUMS algorithm (Gourley et al., 2001).

The period for the case study is from 26 September 2007 00:00 UTC to 27 September 2007 00:00 UTC. For the evaluation of the climatological performance of the radar QPE relative to the rain gauge measurements the period from 15 September 2006 to 10 November 2008 was considered with a data availability of about $80 \%$. In particular, this evaluation was done for the two warm seasons taken as the months from April to September.

\section{Synoptics of the 26 September 2007 case}

The rainfall event which hit the urbanized area of Venice Mestre is to be considered exceptional, both in terms of rainfall intensities (up to $120 \mathrm{~mm} / \mathrm{h}, 90 \mathrm{~mm} / 30 \mathrm{~min}$, and $24 \mathrm{~mm} / 5 \mathrm{~min})$, and overall accumulation $(320 \mathrm{~mm} / 6 \mathrm{~h})$. The synoptic situation was dominated by a surface low located on the Gulf of Genoa associated with an upper-level trough, which advected cold air from Northern Europe towards the Alps and subsequently onto Veneto. The vertical wind shear associated with the trough, along with the instability brought about by the linked cold air advection, gave rise to organized convective activity.

Around midnight first convective cells developed some $20 \mathrm{~km}$ west of Mestre. These were followed by a low-topped supercell exhibiting an echo top between 6 and $7 \mathrm{~km}$ and a clear weak echo region (Fig. 2), typical for this kind of thunderstorm (e.g., Lemon and Doswell, 1979). Interaction of the outflow of this supercell with the south-easterly low-level winds over the adjacent Adriatic Sea formed a convergence line. This line triggered a second low-topped supercell about one hour later which lasted until about 


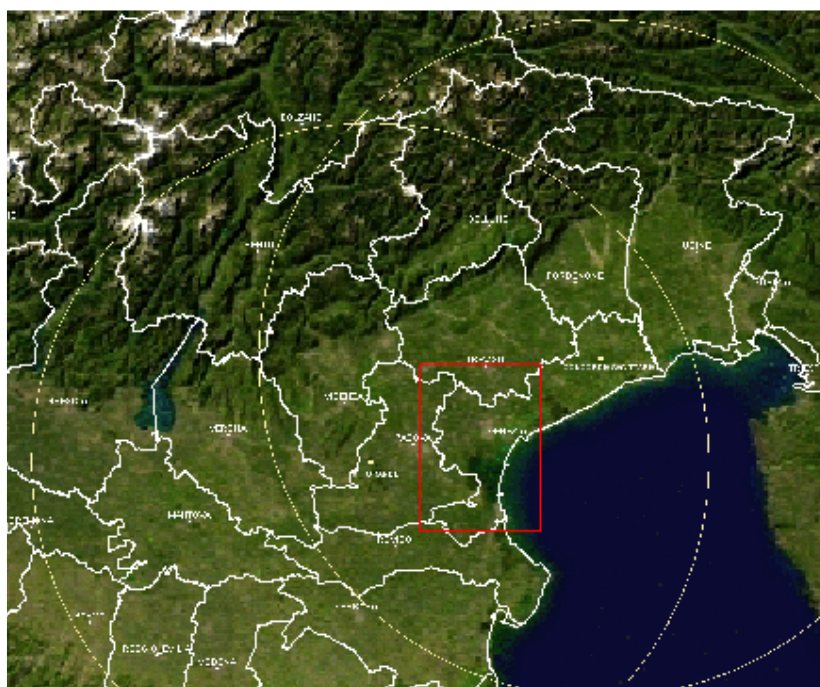

Fig. 1. The political region Veneto is located in north-eastern Italy. The two ARPAV C-band radars are sited at Mt. Grande (472 $\mathrm{m}$ a.s.1.) $25 \mathrm{~km}$ southwest of the city of Padova and Concordia Sagittaria ( $10 \mathrm{~m}$ a.s.1.) $50 \mathrm{~km}$ northeast of Venice $(128 \mathrm{~km}$ range ring indicated). The 26 September 2007 flood event occurred just west of the city of Venice over completely flat terrain. The rectangle denotes the zoom shown in Fig. 7.

03:20 UTC (not shown). Both supercell thunderstorms were associated with high precipitation rates, but still were largely confined west of the area of flooding.

Towards 04:00 UTC the type of convection changed from supercellular to multicellular (Fig. 3) when low-level warm and humid Adriatic air began feeding directly into the system from the east to form a mesoscale convective system (MCS, e.g. Weisman and Klemp, 1982; Schiesser et al., 1995). The flow configuration at this stage was such that the continuous regeneration of convective cells took place in the relatively circumscribed area of some $20 \times 40 \mathrm{~km}^{2}$ around and west of Venice Mestre. The MCS became quasi-stationary for about $4 \mathrm{~h}$, during which the exceptionally high rainfall rates and accumulations were recorded.

After about 08:00 UTC the MCS propagated slowly eastwards and reached the Adriatic Sea by early afternoon. Accordingly, the rain started to decrease after 08:00 UTC and stopped after midday over the area of interest. Note that the MCS still exhibited significant rain intensities throughout the afternoon, but being located over the Sea, they did not add to the hydrological emergency.

The salient features of this event were the very high rainfall intensities, and the overall rainfall accumulation which hit the relatively localized surroundings of the heavily urbanized area of Venice Mestre. Figure 4 shows the daily rainfall accumulation of the ARPAV rain gauge network. Note that these values were not corrected for wind which can lead to significant underestimation (WMO, 1994; Nespor and Sevruk, 1999). The largest accumulations were recorded

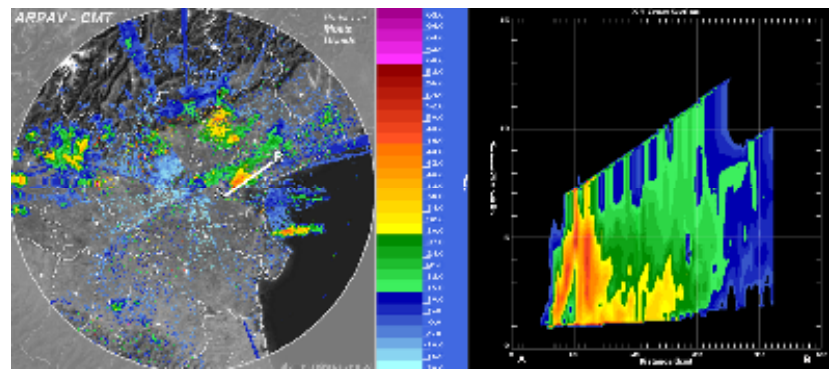

Fig. 2. Reflectivity of the Mt. Grande radar on a quasi-horizontal plane (PPI $0.8^{\circ}$ ) for 26 September 2007 00:40 UTC (left panel) and vertical cross section along the white line A-B. The circle on the left panel correspond to the $128 \mathrm{~km}$ range, and the tick marks on both axes correspond to steps of $1 \mathrm{~km}$.

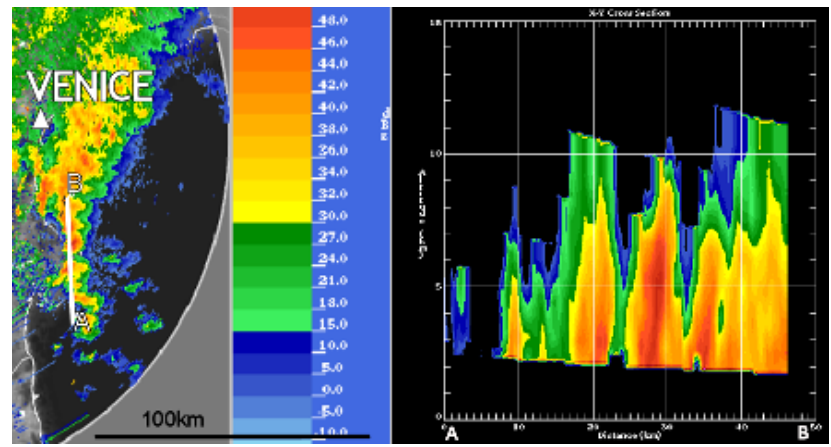

Fig. 3. As in Fig. 2 but for 26 September 2007 08:50 UTC.

at Mestre with $260 \mathrm{~mm}$, and Valle Averto $325 \mathrm{~mm}$, values which were concentrated well within $6 \mathrm{~h}$. The intensities reached values as high as $90 \mathrm{~mm} / 30 \mathrm{~min}, 120 \mathrm{~mm} / 1 \mathrm{~h}$, and $200 \mathrm{~mm} / 3 \mathrm{~h}$.

In summary, the concerted interplay between an upperlevel trough with its associated divergence aloft, the moderate vertical shear in the lower half of the troposphere, the low-level convergence, and the source of warm and humid air from the Sea produced and sustained for several hours this quasi-stationary multicellular MCS.

\section{Radar data analysis}

Deriving precipitation estimates from radars is an ongoing challenge, especially at longer distances from the radar and in complex terrain (Meischner, 2004). The area of Venice Mestre is completely flat and located some $40 \mathrm{~km}$ east of the Mt. Grande radar, i.e. the radar visibility for the area is optimal. As a matter of fact, the ratio of the precipitation accumulation for the April-September months contained in the period 15 September 2006-10 November 2008 for the radar $P_{\text {radar }}$ and eleven rain gauges $P_{\text {gauge }}$ in the area is very 

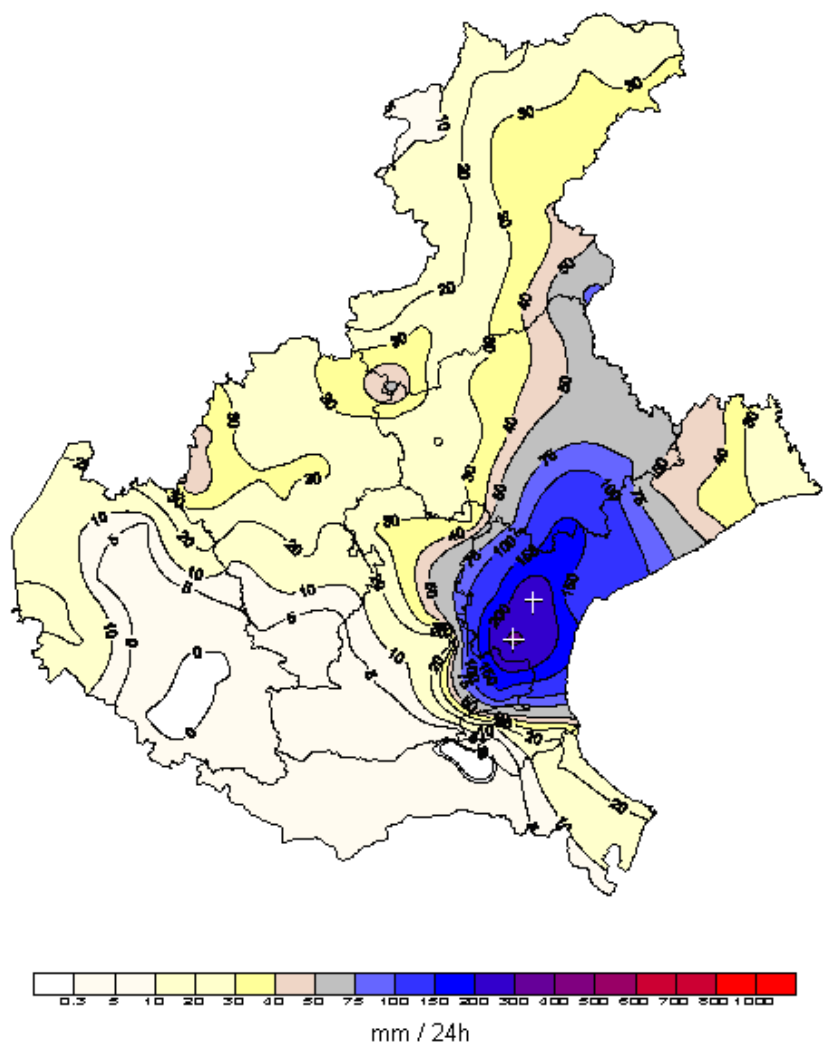

Fig. 4. ARPAV rain gauge network 24-h rainfall accumulation for 26 September 2007. The network consists of 161 tipping bucket rain gauges. The crosses in the area of the rainfall maximum indicate the rain gauge location for stations Mestre (to the north) and Valle Averto (to the south).

close to one. The variability of this correspondence can be measured in decibel, i.e. in the form of

$\mathrm{AF}=10 \cdot \log \frac{P_{\text {radar }}}{P_{\text {gauge }}}$

derived from daily accumulations which are larger than $0.3 \mathrm{~mm}$ for the same data set (Fig. 5 left panel). The radar error cumulative distribution display (Germann et al., 2006) for the occurrence of rain shows a good overall agreement revealing that the median, a robust indicator of the average value, is only slightly positive $(0.18 \mathrm{~dB})$. This indicates that the radar QPE is almost unbiased. The spread, here measured as the distance between the 16th and the 84th percentile, is a bit larger than $\pm 3 \mathrm{~dB}$, i.e. the variability is mostly within a factor of two. The shape of the distribution further indicates that underestimation and overestimation are about in balance. The probability of detection (POD) of rain by the radar at the gauge locations is $95 \%$ with a corresponding false alarm ratio (FAR) of $21 \%$.
The same analysis for higher rainfall accumulations draws a slightly different picture. For an intensity threshold of $10 \mathrm{~mm} / 24 \mathrm{~h}$ (Fig. 5 right panel) the median is very slightly negative $(-0.13 \mathrm{~dB})$ with an overall bias of 0.84 . The spread, on the other hand, is smaller than $\pm 3 \mathrm{~dB}$, indicating less variability. The POD, however, drops to $75 \%$, while the FAR rises to $28 \%$, values that further degrade for the $30-\mathrm{mm} / 24-\mathrm{h}$ threshold.

When looking at hourly accumulations for the 24-h period under investigation, the spread, and therefore the uncertainty, does not increase, it actually decreases slightly, while the median is about $1 \mathrm{~dB}$ (not shown). Examination of the time series of hourly rainfall accumulation for the 26 September 2007 case yields the correspondence between radar and rain gauge for the urban area of Mestre in terms of single radar pixel collocated with the rain gauge location, the mean, the maximum, and the minimum of the $3 \times 3$ radar pixels centered on the rain gauge location (Fig. 6 left panel). Agreement is best during the phases of moderate rainfall, while the single radar pixel corresponding to the rain gauge location underestimates during the highest rainfall intensities between 06:00 and 07:00 UTC. Here the maximum value of the $3 \times 3$ pixels centred around the rain gauge location shows better agreement. Figure 6 right panel draws the same picture for the rain gauge station of Valle Averto.

For a precipitation event of this intensity it is important to assess the effects of attenuation of the C-band radar signals which are converted into QPE. Again, the event under examination is well located as the Mt. Grande radar is sited to the west and the Concordia Sagittaria radar to the east of the main precipitation area offering some degree of redundancy (see Figs. 1 and 7). The signs of evident severe attenuation that emerge from the inspection of the single-radar reflectivity images are not located in the area of maximum rainfall, but rather behind it (not shown). It is likely, though, that the observed values can be thought of as lower limits for the true value. These effects notwithstanding, the 24-h radar QPE accumulation reach maximum values up to $500 \mathrm{~mm}$ and do not coincide with the rain gauge locations. Although the extent of the attenuation is not quantified it is safe to state that its impact on the 24-h accumulation is at best neutral, more likely to underestimate rainfall. This makes it even more probable that the localized radar QPE peaks, which exceed the values retrieved over the rain gauge locations, are indicative for effectively higher rain fall rates.

\section{Conclusions}

In this study consideration was given as to what extent high or very high radar derived QPE values could be taken as flood alert guidance. Such information, provided in real time, can be extremely useful for local civil protection defense activities, which are largely based on precipitation thresholds. The inferences drawn from the single case study performed on an 

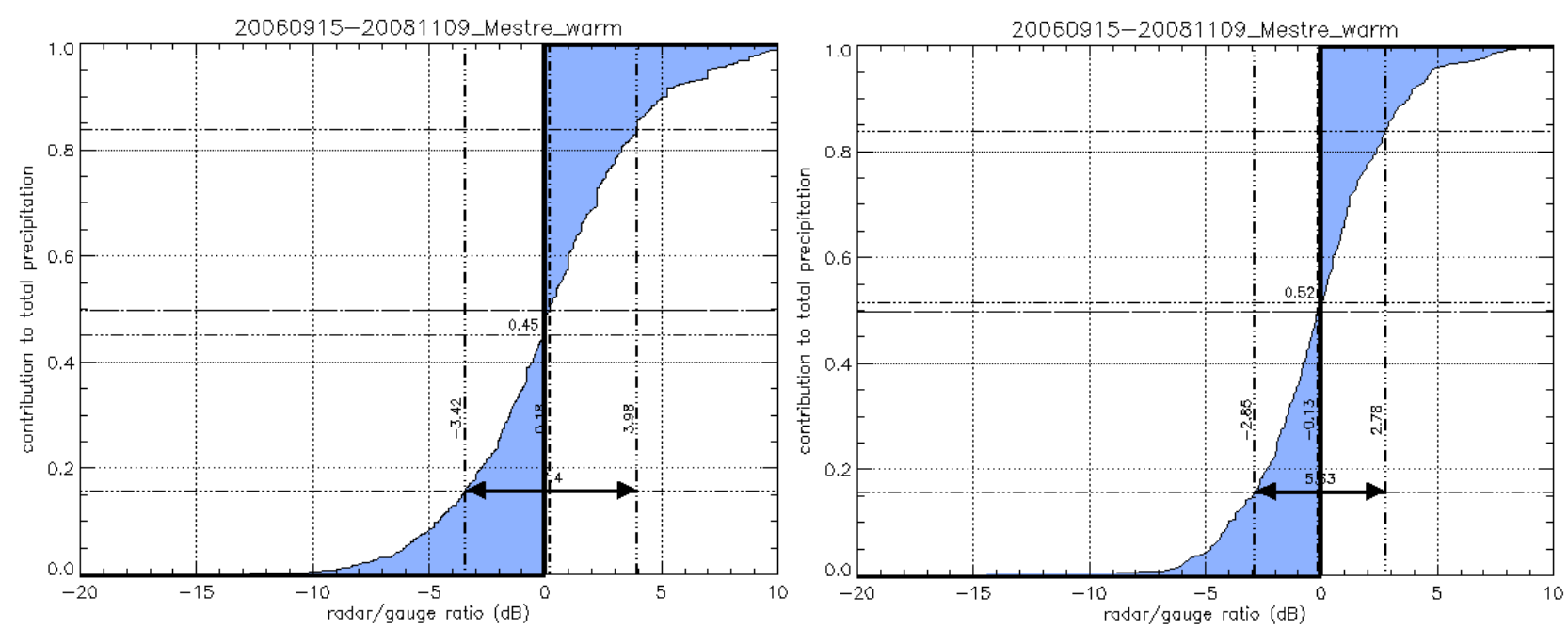

Fig. 5. Error distribution cumulative contribution to total daily rainfall as a function of radargauge ratio (dB) for days with radar and gauge $\geq 0.3 \mathrm{~mm}$ (Germann et al., 2006) for the warm seasons (April-September) within the period 15 September $2006-10$ November 2008 (left panel). Eleven rain gauge stations in the area surrounding Mestre have been included in the analysis. The right panel is for days with intense precipitation defined here as days with radar and gauge $\geq 10.0 \mathrm{~mm}$. The vertical dashed lines delineate the 16th, 50th, and 84th percentile, the continuous bold line the perfect distribution. The percentile values are taken as robust indicators of the mean and the spread of the error distribution.

\section{Mestre - hourly precipitation}

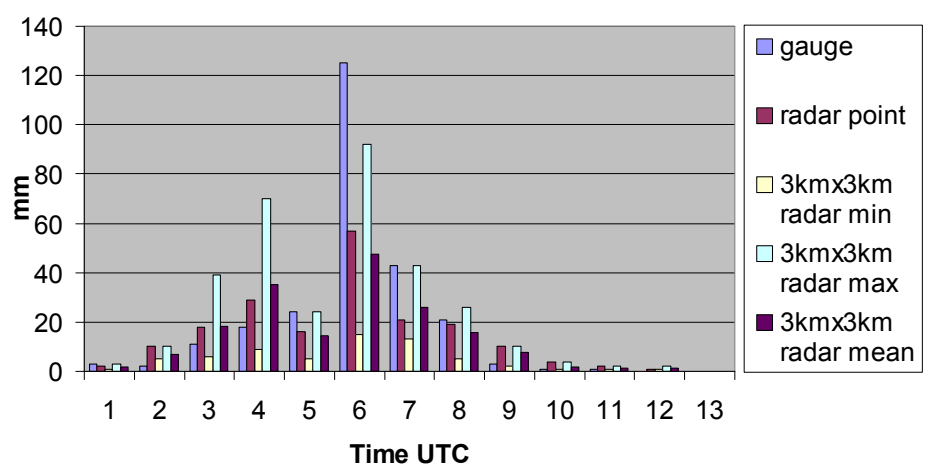

Valle Averto - hourly precipitation

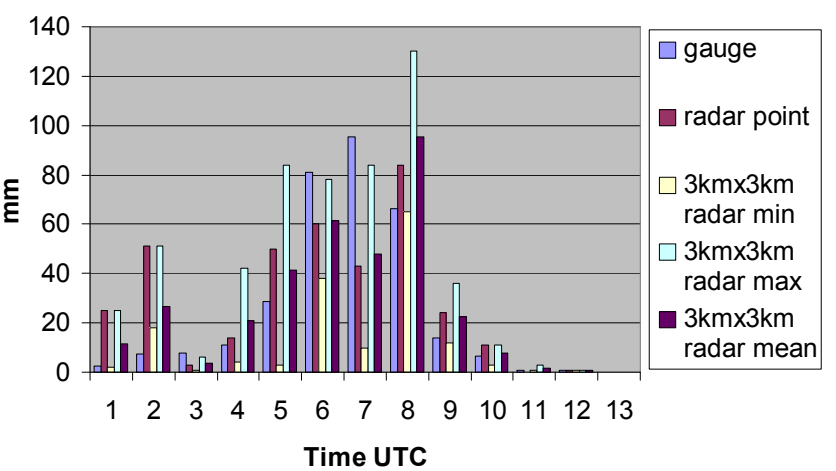

Fig. 6. Comparison of the hourly rainfall accumulation of the Mestre rain gauge (blue bars) with a number of radar-derived product for the first half day of 26 September 2007 (left panel). The purple bars denote the value of the radar pixel corresponding to the location of the Mestre rain gauge station, while the yellow, light blue and dark blue bars refer to the minimum, maximum and average value of the $3 \times 3$ radar pixels centred around the rain gauge location. Right panel for rain gauge station Valle Averto.

exceptional rainfall event, which brought up to $40 \%$ of the mean annual rainfall in only 3-6h, and the two-year statistical analysis, are as follows:

- C-band radars have the potential to quantitatively monitor heavy precipitation events in flat areas which are not located too far from the radar;

- for the larger Mestre area and for the two warm seasons 2007 and 2008 the radar to gauge comparison gives better results for only intense daily precipitaton accumulation, when compared to the precipitation occurrence (i.e. including light and moderate precipitation); however, probability of detection (POD) decreases and false alarm ratio (FAR) increases for the higher precipitation intensities;

- comparison of hourly radar with the rain gauge accumulations for the event shows good agreement for moderate rainfall intensities, and underestimation of the radar for the highest rainfall intensities;

- the locations of the maximum 24-h rainfall accumulation in the radar QPE and the rain gauge network do not 


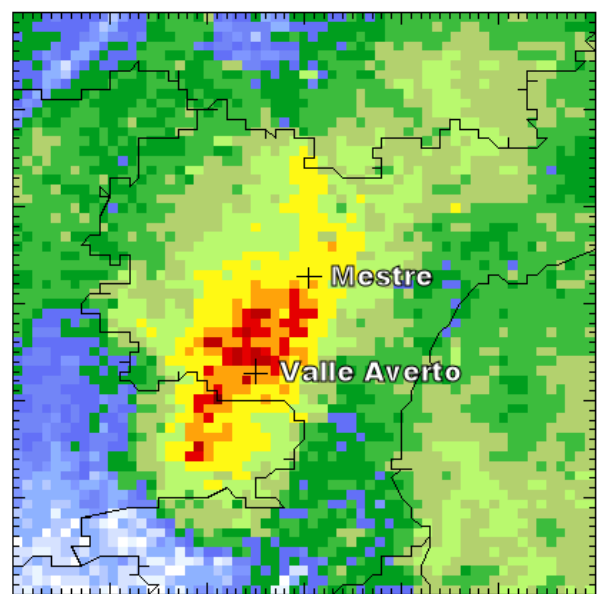

$\begin{array}{llllllllllllllll}1 & 1.6 & 2.5 & 4 & 6.3 & 10 & 16 & 25 & 40 & 63 & 100 & 160 & 250 & 300 & 350 & 400\end{array}$

Fig. 7. 24-h radar QPE accumulation (in $\mathrm{mm}$ ) for the ARPAV composite as processed by the HDSS QPESUMS algorithm. The geographical zoom is indicated in Fig. 1. Note that the precipitation scale is logarithmic up to $160 \mathrm{~mm}$ and then linear. The crosses in the area of the rainfall maximum indicate the rain gauge location for stations Mestre (to the north) and Valle Averto (to the south). The tick marks denote the $1 \mathrm{~km}$ grid on which the radar QPE is analyzed.

coincide, a fact that suggests that this area has received even more rainfall than what was recorded by the rain gauge network;

- further evaluation of radar-based flash flood guidances for the flat area of the Venice Province seems worthwhile.

The quantification of the uncertainty in the radar-derived QPE is extremely difficult, especially for exceptional and therefore rare precipitation intensities like those presented for this case. Statistically, a spread of $\pm 3 \mathrm{dBZ}$ centred around a median of $0 \mathrm{dBZ}$ means that half of the time the radar sees typically between $50-100 \%$ and half of the time between $100-200 \%$ of what the gauge records. Less frequently these discrepancies are even larger. The fact that POD and FAR are less favorable for higher intensities, when this information becomes important, adds to the uncertainty. However, for the case presented here the very high intensities, as observed by the radar, are compatible with the hydrological and hydraulic effects observed. In a flat and densely populated area like the Po Valley concentration times for catchments are in the order of $12 \mathrm{~h}$, i.e. the surface runoff is relatively slow and hydrological response can be very local and not confined to particular portions of the watershed. Therefore, signalling such localized rainfall maxima, typical for convective events and which can be missed even by dense rain gauge networks, constitutes a relevant piece of information to judge the probability of local flooding and manage civil protection activities.
The case study character of the present work constitutes a clear limitation. Longer periods will be analyzed in order to increase the statistical significance of the radar-to-gauge correspondence for the relevant higher precipitation accumulation thresholds. Also, the cold season precipitation, which can lead to even greater hydrological hazard, are not addressed by the presented statistical analysis. These events, however, are characterized by more widespread and longerlasting precipitation, and are typically fairly well captured by current high-resolution rain gauge networks.

Acknowledgements. The authors would like to thank G. Formentini for preparing the radar imagery and the discussions on convective dynamics.

Edited by: S. Michaelides, K. Savvidou, and F. Tymvios Reviewed by: three anonymous referees

\section{References}

Conway, J. W., Barerre, C., Formentini, G., Lago, L., Rossa, A., and Calza, M.: Flash Flood Prediction in Italy: Development and Testing of a New Capability, in: Proceedings of 21st Conference on Hydrology, AMS Annual, AMS, available at: http://ams.confex.com/ams/pdfpapers/121128.pdf, 2007.

Germann, U., Galli, G., Boscacci, M., and Bolliger, M.: Radar precipitation measurement in a mountainous region, Q. J. Roy. Meteor. Soc., 132, 1669-1692, 2006.

Germann, U., Berenguer, M., Sempere-Torres, D., and Zappa, M.: REAL-Ensemble radar precipitation estimation for hydrology in a mountainous region, Q. J. Roy. Meteor. Soc., 135, 445-456, available at: http://dx.doi.org/10.1002/qj.375, 2009.

Gorgucci, E. and Chandrasekar, V.: Evaluation of Attenuation Correction Methodology for Dual-Polarization Radars: Application to X-Band Systems, J. Atmos. Ocean. Tech., 22, 1195-1206, available at: http://dx.doi.org/10.1175\%2FJTECH1763.1, 2005.

Gourley, J., Zhang, J., Maddox, R. A., Calvert, C. M., and Howard, K.: A real-time precipitation monitoring algorithm - Quantitative Precipitation Estimation and Segregation Using Multiple Sensors (QPE-SUMS), in: Preprints, Symp. On Precipitation Extremes: Predictions, Impacts, and Responses, AMS, AMS, albuquerque, NM, 57-60, 2001.

Hitschfeld, W. and Bordan, J.: Errors inherent in the radar measurement of rainfall at attenuating wavelengths, J. Atmos. Sci., 11, 58-67, 1954.

Illingworth, A.: Weather Radar: Principles and Advanced Applications, in: chap. Improved precipitation rates and data quality by using polarimetric measurements, monograph series "Physics of Earth and Space Environment", Springer, 337 pp., 2004.

Italian-Government: Legge 24 febbraio 1992, n. 225, available at: http://www.protezionecivile.it, 1992

Italian-Government: Legge 11 dicembre 2000, n. 365, available at: http://www.protezionecivile.it, 2000.

Italian-Government: Dir. P.C.M. 27 febbraio 2004, available at: http://www.protezionecivile.it, 2004.

Lemon, L. R. and Doswell, C. A.: Severe Thunderstorm Evolution and Mesocyclone Structure as Related to Tornadogenesis, Mon. Weather Rev., 107, 1184-1197, 1979. 
Meischner, P. (Ed.): Weather Radar: Principles and Advanced Applications, monograph series "Physics of Earth and Space Environment”, Springer, 337 pp., 2004.

Michelson, D., Einfalt, T., Holleman, I., Gjertsen, U., Friedrich, K., Haase, G., Lindskog, M., and Szturc, J.: Weather Radar Data Quality in Europe: Quality Control and Characterization, ERAD-3, Visby, Sweden, 6-10 September 2004.

Nespor, V. and Sevruk, B.: Estimation of Wind-Induced Error of Rainfall Gauge Measurements Using a Numerical Simulation, J. Atmos. Ocean. Tech., 16, 450-464, 1999.

Rossa, A., Liechti, K., Zappa, M., Bruen, M., Germann, U., Haase, G., Keil, C., and Krahe, P.: Uncertainty Propagation in Advanced Hydro-Meteorological Forecast Systems: The COST 731 Action, Atmos. Res., in press, 2010.

Rotach, M. W., Ambrosetti, P., Ament, F., Appenzeller, C., Arpagaus, M., Bauer, H.-S., Bouttier, F., Buzzi, A., Corazza, M., Davolio, S., Denhard, M., Dorninger, M., Fontannaz, L., Frick, J., Fundel, F., Germann, U., Gorgas, T., Hegg, C., Hering, A., Keil, C., Liniger, M. A., Marsigli, C., McTaggart-Cowan, R., Montani, A., Mylne, K., Ranzi, R., Richard, E., Rossa, A., Santos-Muñoz, D., Schär, C., Seity, Y., Staudinger, M., Stoll, M., Volkert, H., Walser, A., Wang, Y., Werhahn, J., Wulfmeyer, V., and Zappa, M.: MAP D-PHASE: Real-time Demonstration of Weather Forecast Quality in the Alpine Region, B. Am. Meteorol. Soc., 90, 1321-1336, 2009.
Schiesser, H., Houze, R., and Huntrieser, H.: The Mesoscale Structure of Severe Precipitation Systems in Switzerland, Mon. Weather Rev., 123, 2070-2097, 1995.

Sempere-Torres, D., Pegram, G., Llort, X., Velasco-Forero, C., and Franco, M.: Real-time assessment of accuracy and quality in quantitative precipitation estimation, in: Proceedings of Fifth European Conference on Radar in Meteorology and Hydrology (ERAD2008), Helsinki, Finlàndia, ERAD Publication Series, vol. 4, ISSN: 978-951-697-676-4, 2008.

Testud, J.: Weather Radar: Principles and Advanced Applications, in: chap. Precipitation measurements from space, monograph series "Physics of Earth and Space Environment", Springer, 337 pp., 2004.

Weisman, M. and Klemp, J.: The Dependence of Numerically Simulated Convective Storms on Vertical Wind Shear and Buoyancy, Mon. Weather Rev., 110, 504-520, 1982.

WMO: Guide to hydrological practices, data acquisition and processing, analysis, forecasting and other applications, Tech. Rep. 168, WMO report No. 168, ISBN 92-63-15168-7, 1994.

Zappa, M., Rotach, M. W., Arpagaus, M., Dorninger, M., Hegg, C., Montani, A., Ranzi, R., Ament, F., Germann, U., Grossi, G., Jaun, S., Rossa, A., Vogt, S., Walser, A., Wehrhan, J., and Wunram, C.: MAP D-PHASE: real-time demonstration of hydrological ensemble prediction systems, Atmos. Sci. Lett., 9, 80-87, available at: http://dx.doi.org/10.1002/asl.183, 2008. 